BULLETIN Bulletin hispanique

HISPANIQUE Université Michel de Montaigne Bordeaux

109-2 | 2007

La formation du Parnasse espagnol $\mathrm{XV}^{\mathrm{e}}-\mathrm{XVIII}{ }^{\mathrm{e}}$ siècle

\title{
A las poéticas cumbres coronadas
}

la orogelatría impresa del Parnaso áureo

\section{Víctor Infantes}

\section{(2) OpenEdition}

\section{Journals}

Edición electrónica

URL: http://journals.openedition.org/bulletinhispanique/476

DOI: 10.4000/bulletinhispanique.476

ISSN: 1775-3821

Editor

Presses universitaires de Bordeaux

\section{Edición impresa}

Fecha de publicación: 1 diciembre 2007

Paginación: 449-472

ISBN: 978-2-85276-096-7

ISSN: 0007-4640

Referencia electrónica

Víctor Infantes, «A las poéticas cumbres coronadas », Bulletin hispanique [En línea], 109-2 | 2007,

Publicado el 01 diciembre 2011, consultado el 27 abril 2019. URL : http://journals.openedition.org/

bulletinhispanique/476 ; DOI : 10.4000/bulletinhispanique.476

Este documento fue generado automáticamente el 27 abril 2019.

Tous droits réservés 


\title{
A las poéticas cumbres coronadas
}

\author{
la orogelatría impresa del Parnaso áureo
}

\section{Víctor Infantes}

1 El Parnaso es una de las pocas marcas con denominación de origen en la mercadotecnia cultural europea de los Siglos de Oro, y cuando arriba a los ámbitos españoles llega con una contrastada publicidad de sus méritos y habiendo superado diferentes controles de calidad y eficacia. Se vende, simplemente con mencionar su nombre, en cualquier plaza de abastos y con ella negocian tratantes lisonjeros, asentadores con panoplia e intermediarios con cédulas de contratación. En realidad, y perdón por las alegorías comerciales que me propongo abandonar enseguida, cuando mencionamos el Parnaso no se trata sólo de una marca, sino de un holding con muy distintas ramificaciones y filiales que se caracteriza por dos valores siempre en alza: su cotización es uno de los patrones seguros de referencia de los siglos áureos y circula libremente sin IVA por la bolsa europea de valores. Hablamos, como es fácil suponer, de una de las industrias del lujo cultural de la época, donde parece más que necesario poseer cierta formación lectora y haber realizado algún máster de mitología. Armado, pues, de ciertas referencias imprescindibles, puede uno entonces acercarse hasta las estribaciones de su nombre y comenzar la ascensión hacia ese pináculo que era «tanto alongado de ocçidente commo de oriente et ay en él dos collados con dos cabeças tan altas que con las nuues contienden», que son las palabras de Alfonso X en su General Estoria con las que probablemente se inaugura en castellano hacia finales del siglo XIII la mención del monte Parnaso ${ }^{1}$.

2 Mencionar Parnaso en los siglos XVI y XVII es nombrar la bicha y poner a prueba los thesaurus de referencias -en google ayer no bajaban de cuarto de millón los links que había que desbrozar- $y$ a todas luces resulta imposible abordar una (aunque sea) breve historia de esa orogelatría impresa que se desarrolla en nuestros Siglos de Oro, ni siquiera una panorámica puntual por temas o por cronologías; por tanto me limitaré, por convencimiento propio y por exigencias obligadas del guión, a recorrer algunos de los múltiples testimonios que nos ha dejado ese furor editorial grabado en las prensas por incluir a toda costa el nombre de esta lejana cordillera helénica. 
3 No es nada nuevo recordar, para nuestros Siglos de Oro, que la voz, el término y la idea del Parnaso incluye una oferta de muy diversos significados, ofrecidos (también) por muy diferentes personas y propósitos, sin que pueda establecerse con sobrada nitidez -salvo los parnasos nominales y autoproclamados de los que luego mencionaremos algunos de los ejemplos más significativos- unas relaciones directas de dependencia, fuente o comparación. La idea del monte de la fama y de la expresión máxima de la querencia poética corre por los entramados culturales áureos más o menos libre de una contaminación efectiva, en cuanto que directa, tanto por el uso de tal o cual autor como por la mención reiterativa del prestigio de su conocimiento. En un reciente estudio, Vélez-Sainz ha recordado que el lexema se utiliza de forma continua, pero también cambiante a lo largo de todo el Siglo de Oro $^{2}$; por ello creemos que se utiliza indiscriminadamente como una suerte de modelo (y también como tópico) referencial que acomoda por igual, y a satisfacción del usuario, intereses culturales muy distintos.

Valga como mero repaso (espero que) de todos conocido, que el Parnaso sirve como concepto ideológico, aplicable entonces a cualquier sistema mnemotécnico de organización enunciativa; vale asímismo como asimilación de un topoi cultural de (posible) utilización política, relacionando entonces para su aplicación explícita unos diagramas de equivalencias mitológico/monárquicas de tintes nacionalistas y tiene, también, una amplísima manifestación plástica que ofrece la representación visual de su configuración mítica, de nuevo por medio de un programma de alegorías visuales que establece un modelo iconográfico de sus elementos más significativos. La amplitud epistemológica de estas características permite una aplicación constante en los diferentes sistemas literarios áureos, con especial relevancia en lo poético (y en lo metapoético), sin olvidar tampoco el componente irónico y paródico, que satiriza y denuncia un uso (y abuso) continuado. Así, toda la representación cartográfica de la topografía parnasiana, unida a la ubicación escenográfica de los loci y de los dramatis personae que la habitan: Apolo, el Templo, la Fuente Castalia, el Helicón, la congregación de las Musas, Pegaso, etc. proporciona una cosmografía que permite establecer unas relaciones icónicas y gráficas en la que (además) interviene una textualidad superpuesta que mezcla tradiciones, altera características, bien por manejar fuentes diferentes bien por utilizar tan sólo algunos motivos específicos, o transgrede abiertamente la combinación de los elementos establecidos.

5 Se presenta, pues, como la maqueta ideológica de una topografía hipotética, evocada desde el imaginario ensoñado de (casi) todos los hombres de letras -y muy especialmente de los poetas, como representantes de su cosmogonía-, donde el Parnaso orográfico y mitológico de la tradición clásica adquiere paulatinamente en los Siglos de Oro las características de un Parnaso imaginario y utópico que se transforma según los intereses de su aplicación efectiva. Sirve, pues, como una geografía onírica donde se ubica la preceptiva de unas coordenadas axiales más o menos homogéneas, porque proporciona una imagen de armonía y permanencia, avalada por el propio prestigio de su transmisión. Es irremediable, por tanto, mencionar una palabra, en la medida que encierra un concepto que va mucho más allá del lexema, y que responde a la necesidad de nombrar esta apología de un sistema poético perfectamente construido, ordenado y mantenido en los límites de la topografía parnasiana, y que no es otra que la de canon ${ }^{3}$.

6 Nos recordaba acertadamente uno de los responsables de nuestro Coloquio en un trabajo nuclear sobre el asunto que: «Cualquier consideración acerca del funcionamiento de los mecanismos canónicos y canonizadores en los siglos de oro debe partir de una obviedad: 
la de la existencia y mantenimiento, con mayor o menor capacidad de referencia, de un canon clásico, heredado del periodo helénico, mantenido sin apenas alteraciones en el periodo medieval y levemente modificado por la acción de los humanistas $»^{4}$. Por ello, y por la asimilación que evidentemente se debe (y se puede) establecer entre parnaso y canon, ambos se presentan como modelos referenciales de aplicación teórica y práctica; recuerda (y resume) Vélez-Sainz que: «La formación del Parnaso, el mito clásico que refleja la República de las Letras, permite, ya desde la Antigüedad, la descripción de la formación de lo que hoy llamaríamos un canon que se forma activamente con cada nueva generación que negocia su posición dentro del sistema» ${ }^{5}$.

7 No se preocupen. No van a ir mis ascensiones parnasianas por estos campos de la hermenéutica, la exégesis y la teoría retórica, que no por trillados y roturados van a darnos mejores frutos (de los que ya nos han dado), sino que tiro de «reportorio de caminos» y andaré esta jornada cercando algunos de los pormenores de una recopilación impresa donde el Parnaso figura como reclamo poético, pero también como señuelo editorial.

La numerosa tipología del Parnaso áureo permite diseccionar los testimonios conservados siguiendo unas clasificaciones que necesariamente se tiene que establecer desde la lectura de las obras, partiendo de la significativa formulación de los títulos -y hablando de libros impresos este elemento es de una importancia primordial- y de las declaraciones prohemiales en los paratextos, hasta la confrontación de la realidad reflejada en las propias obras; características, repito (e insisto), que son las que nos revelan los testigos impresos y no las clasificaciones apriorísticas que luego hay que calzar con los textos que conviene. Cuando una obra, tanto por su autor como por su recopilador, se quiere voluntariamente adscribir a la geografía del Parnaso se suele expresar con toda claridad enunciativa y son a éstas a las que dedicaré ahora mi atención, dejando al margen aquellas otras que su posible condición parnasiana viene pespunteada en un envoltorio metafórico que necesita una descodificación no siempre satisfactoria y, sobre todo, no siempre tan evidente. Perdonen (o no perdonen), pues, las citas que continúan ${ }^{6}$, pero hay mucho libro impreso en la biblioteca imaginada de este peñasco situado entre la Fócida y la Dórida.

9 Una de las acepciones más importantes, y más generosamente utilizada en los Siglos de Oro, es, sin duda, la de la conceptualización del Parnaso como sinónimo de una antología poética, antología que se identifica con la clara voluntad de situar la obra al amparo de las virtudes literarias emanadas de la monarquía de Apolo; quizá por principio tendría que ser única e irrepetible, puesto que debería representar a la propia República de las Letras, a la nómina de los autores laureados y a los textos que forman el referente de cualquier imitación posterior. No obstante, un trecho temporal de dos siglos permite, entonces, la paradoja de la existencia de diferentes Parnasos a lo largo de tanto tiempo de actividad literaria, actualizando secuencial $\mathrm{y}$, sobre todo, temáticamente, la vigencia de las diferentes opciones escogidas; porque ya sabemos que las obras pueden ser de fama eterna, pero los poetas se suelen morir antes o después y no hay más remedio que ir renovando el cotarro literario.

10 Por ello conviene deslindar dos grupos nítidamente separados: el de las recopilaciones poéticas que se corresponden con una idea expresamente señalada de constituir(se en) un Parnaso y el de aquellas otras que ni pretenden ni mencionan una voluntad explícitamente parnasiana. En este segundo lado quedan, con toda lógica, los numerosísimos cancioneros, cartapacios y cuadernos áureos, productos voluntariamente 
aleatorios, sometidos a la selección personal y (por tanto) caprichosa de su recopilador o recopiladores; lado que extendemos también a las academias, justas, certámenes, honras, exequias y recibimientos, productos, en general, relacionados con una temática y con una motivación previa, que condiciona o determina la presencia nominal de unos $u$ otros autores y textos. Valga recordar que suelen carecer de prólogos y justificaciones que pretendan situar estas congregaciones poéticas al amparo de la mitología literaria del Parnaso, al contrario de las que voluntariamente se sitúan de lleno en su paradigma cultural; con la excepción esporádica del uso de la titulación, debida en algunas ocasiones -como luego mencionaremos- a un librero, a un impresor o, simplemente, a un «aficionado», pero sin venir refrendada en un proemio justificativo, o en la incorporación ocasional de algunos textos que agregan elementos temáticos vinculados tangencialmente con el tema parnasiano.

11 Es obligada la cita de tres de las antologías más significativas de los Siglos de Oro, que de nuevo Pedro Ruiz nos recuerda al abordar su condición canónica, pues no en vano aparecen como «muestrarios escogidos de la poesía que se presentan como innovación o modelo estilístico, con una gradación evidente en los tres referentes más destacados a lo largo de un siglo: el Cancionero general de 1511, el Cancionero de obras nuevas de 1554 [en este tramo cronológico sumaremos nosotros la Floresta de Ramírez Pagán de 1562] y las Flores de poetas ilustres de 1605, representativas respectivamente de la tradición octosilábica, carente hasta entonces de reconocimiento de su dignidad; de su encuentro con los modelos italianos, en un proceso de ennoblecimiento, y, finalmente, de la conciencia de una cierta sublimidad en los logros estilísticos» ${ }^{7}$. Quizá debemos exiliarlas del Parnaso, pues nada se atisba de una ceremonia alpina en las presentaciones (o justificaciones) de estas magnas florestas de la lírica áurea y que más de un lector situaría como prototipos del Parnaso hispano, porque, salvo explícita declaración de intenciones hostiles, estas antologías huyen de la ceremonia textual de la consagración.

Hernando del Castillo en el Cancionero general de muchos y diversos autores (Valencia, Cristóbal Kofman, 1551; fol., 8 hs.+234 fols.) tan sólo insiste en el «Prólogo» en ensalzar su diligencia acumulativa en la "recopilación o cancionero», eco casi medieval de sus intenciones estéticas, con la que pretender proteger a sus casi 1.100 textos que «desde Juan de Mena acá se escrivieron», a los que aplica un sistema de "partes y distinciones de materias ${ }^{8}$, y el Cancionero general de obras nuevas nunca hasta aora impressas. Assí por ell arte Española, como por la Toscana. (Zaragoza, Esteban de Nájera, 1554; 12², 203 fols.) carece de presentación, y es más, ya anuncia en la propia portada del libro el primer texto que aparece tras la portada: «Y esta primera es el Triumpho de la muerte traduzido por Juan de Coloma», señal de una voluntad editorial ajena a las contiendas teóricas?

Tampoco se dice nada significativo en la Floresta de varia poesía. Contiene esta Floresta que componía el doctor Diego Ramírez Pagán, muchas y diversas obras, morales, spirituales y temporales, y esta primera es una elegía en la muerte del Emperador nuestro rey y señor (Valencia, Juan Navarro, 1562; $8^{\circ}, 200$ hs.) ${ }^{10}$, ni en las «Epístolas» que abren la obra, la dedicada al Duque de Seborge (destinatario del libro), en la que suelta sus fantasmas literarios y vuelve al envoltorio tradicional («El quaderno de mis obras...») y se autocensura por sus faltas, puesto que se (auto)presenta como «Theólogo y Sacerdote indigno» (I, pp. 32-36); ni en la dirigida a Juana de Austria, como excusa lacrimógena por la muerte del Emperador (I, pp.36-37); ni en la de Leonor Gálvez, en la que ya no es «indigno» (II, p. 93); ni, muy especialmente, en el consabido texto de «El auctor a los lectores», pospuesto hasta la mitad del libro (II, pp. 13-14), donde descarga la consabida 
apología de autoridades que le precedieron como nómina recurrente ${ }^{11} \mathrm{y}$ donde anuncia una segunda parte de la obra ya «en poder de los impressores», que no salió jamás, y que llevaba, entre otros textos, todas las epístolas de Ovidio traducidas al español. Ni mucho menos Pedro de Espinosa en una brevísima presentación «Al lector» (5r-6r), sin firmar, de la Primera parte de las Flores de poetas ilustres de España, dividida en dos libros (Valladolid, 1605; 4, 8 hs.+ 204 fols. +4 hs.), insiste en nada parnasiano y sólo presta atención a un asunto de referencia de prestigio y autoritas, y muy probablemente comercial, que de nuevo, también se expresa en la portada, y es que «van escritas diez y seis Odas de Horacio, traducidas por diferentes y graves Autores, admirablemente» ${ }^{12}$. $\mathrm{Ni}$ tampoco, por cierto, en la manuscrita Segunda parte de Flores de Poetas ilustres de España, ordenada por Juan Antonio Calderón ${ }^{13}$.

Si retornamos a los Parnasos antológicos con vocación poética y programática explícita tendríamos que empezar por los que eliminamos. No es escaso el número de obras que acogen bajo su tutela la rotulación parnasiana, pensamos que en casi todas las ocasiones para dotar de prestigio -desde el primer contacto con su título- tanto la recopilación de una obra literaria personal, como la labor antológica de las obras de otros; caso evidente de dos recopilaciones de romancero que sólo tienen de Parnaso el aprovechamiento de su mención, quizá con un sentido netamente comercial. La primera es la debida al librero ¿toledano? Luis de Medina, responsable editorial de unas Flores del Parnaso. Octava parte del Romancero general (Toledo, Pedro Rodríguez, 1596; 12 6 hs. +150 fols.), que utiliza esa titulación sólo en esta parte, sin justificación alguna en el no prólogo, a pesar de llevar «Licencia» de Juan Rufo, de quien es precisamente el primer poema («La trágica y lamentable historia de los Comendadores, y venganza de Don Fernando, Veynticuatro de Córdova. Repartida en cinco Romances») ${ }^{14}$. La segunda son las Maravillas del Parnaso y flor de los mejores romances graves, burlescos y satíricos que hasta oy se han cantado en la Corte. Recopilados de graves autores, recopilada por el "Capitán entretenido» Jorge Pinto de Morales (Lisboa, Lorenzo Craesbeeck, 1637; $8^{\circ}, 2$ hs. +96 fols. +2 hs.), que vuelve al intento de otorgar autoridad literaria a un antología romanceril de las muchas que se recopilaron en el siglo XVII ${ }^{15}$.

Mejor excusa es la de Diego Mexía de Fernangil cuando aprovecha, por su ubicación peruana, el controvertido «Discurso en loor de la Poesía, dirigido al autor, y compuesto por una señora principal d'este Reino» (fol. 9r-26r) que portica su traducción de Ovidio para titular unitariamente la obra como Primera parte del Parnaso Antártico de obras amatorias. Con las 21 Epístolas de Ovidio y el In Ibin en tercetos (Sevilla, Alonso Rodríguez Gamarra, 1608; 4, 7 h.+268 fols. ${ }^{16}$; quizá con el único intento de aplicar un rótulo ya establecido hacia su proyección en el continente americano, digamos (sin más aclaraciones) que para su particular ubicación en un nuevo Parnaso ${ }^{17}$. Se puede corroborar esta voluntad indiana por la existencia de una Segunda parte del Parnaso antártico de divinos poemas (Bibliothèque Nationale de France, Mss. Esp. 389; 4ํㄱ 209 hs.) dirigida al Príncipe de Esquilache, Francisco de Borja, en Potosí, el 15 de enero de 1617 y donde el autor se presenta como natural de Sevilla y «Ministro del Sancto Officio de la Inquisición en la visita y corrección de los libros»; consta de una extensa colección de sonetos a la Vida de Christo (hs. 1r-101v) y otra de poemas religiosos (hs. 102r-195v), dedicados a Alonso Maldonado de Torres, Presidente de la Real Audiencia de Las Charcas y Oídor del Consejo Real, a Doña Leonor de la Trinidad, Abadesa del Monasterio de San José en Reyes y a Diego de Portugal, Consejero del Rey. 

tardío de Don Francisco de Quevedo, el jienense Juan del Valle y Caviedes, que nos legó una más que curiosa apropiación del rótulo de nuestra montaña para apadrinar una de sus obras más conocidas: el Diente del Parnaso, que trata dibersas materias contra Médicos, versos amorosos, a lo divino, pinturas y retratos, furiosa diatriba contra los galenos, terminada entre 1689 y 1691, y cuyo sentido semántico dejo a gusto de quien le quiera hincar el lexema odontológico. En el original manuscrito, ya que el texto nunca vio la luz impresa en su momento, se incluye toda una serie de paratextos irónicos y mordaces, cuya existencia no implica necesariamente que estuviera preparado para una hipotética impresión; caso de la «Dedicatoria»: «Dedícalo su autor a la Muerte, emperatriz de médicos, a cuyo augusto y pálido cetro le feudan vidas y tributan saludes en el tesoro de muertos y enfermos»; el «Privilegio»: «Tiene por toda su vida / el autor de este cuaderno / privilegio de imprimirlo,/ porque la vida va en ello» y una irónica y divertidísima «Fe de erratas» que no me resisto a recordar ${ }^{18}$ :

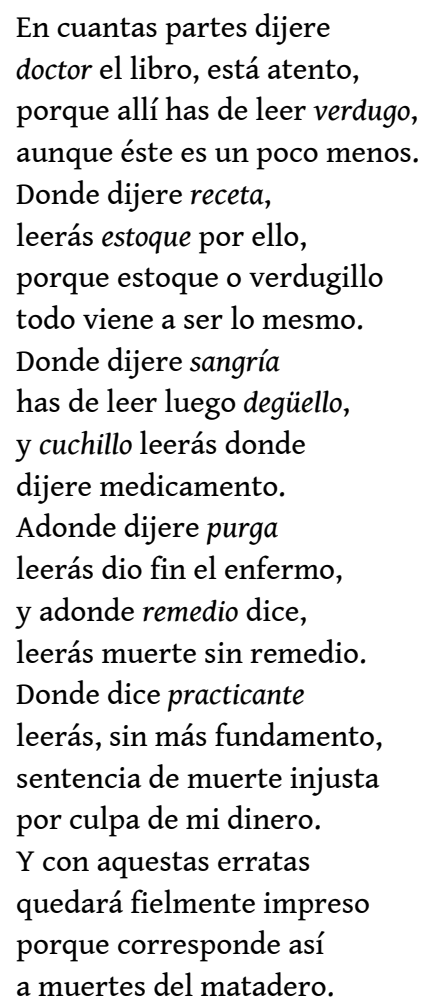

Si después de esta excursión antártica volvemos a la Península con otros ejemplos, hay que señalar otra excusa más que llamativa y acomodaticia, en esta ocasión, para una colección de novelas, pues en El Curial del Parnaso. Primera parte (Madrid, Viuda de Cosme Delgado, 1624; $8^{\circ}$, 8 hs. +170 fols. +2 hs.), no hay Segunda ni tampoco las seis comedias que promete que pronto saldrán, toda la vinculación con el Parnaso se reduce a señalar en el consabido texto «Al lector», que estos "Avisos remití desde el Parnaso de mi estudio al dueño que los dirijo» ${ }^{19}$. Es más que curioso indicar que el autor, en los textos prohemiales de su pluma, la «Dedicatoria» a Nicolás Barrantes Arias del Consejo de su Magestad y la ¿epístola? antes citada, firmada por el propio título «El Curial», llama a su obra «Avisos» quizá con las sombra de Boccalini en la memoria, pues Barrionuevo es más tardío-, mientras que los textos legales, la «Tasa», la «Licencia», el «Privilegio» y la «Fe de erratas», la denominan unitariamente "Curial del Parnaso», lo que parece denunciar un cambio nominal de última hora, una vez compuestos los «Avisos». 

pertenencia genérica, una Academia y unas Honras fúnebres, quedan fuera de la conceptualización (teórica) del mismo, pero que sus recopiladores quieren dotar de una justificación especial para que se inserten de lleno en la República de las Letras. En el primer caso se trata del Nuevo Parnaso. Iunta yngeniosa de cortesanas musas. Celebrada en Casa de Don Álvaro de Cabrera, Capitán de Cavallos Coraças (Nápoles, s. i., 1660; 4º 2 hs.+42 fols.), «dispuesta por Antonio de la Cueva», donde se recoge una nómina de cerca de 20 poetas con sus noticias biográficas, dedicada a Francisco Garrafa, Príncipe de Belveder, y que se presenta -a las alturas ya de mediado el siglo XVII y fuera de España- como la formación de un Parnaso reverdecido y (nuevamente) renovado. celebración impresa de un Parnaso de eterna fama mortuoria: Memoria fúnebre y exequias del Parnaso, celebradas por diversos Apolos, a la posteridad de la Señora Doña Agustina Rizo y Portillo Méndez de Sotomayor, cuya lúgubre harmonía dedica al sentimiento de Don Juan de Ovando y Santarén Gómez de Loysa su esposo (Málaga, Mateo López Hidalgo, 1665; 4º 5 hs.+ 98 fols.); se trata de una extensa antología en honor de la esposa ausente, con todos los poetas equiparados como «Apolos», incluido el propio marido, que tiene un grupo propio de poemas elegíacos ${ }^{20}$. De todas maneras a este malagueño, Caballero de Calatrava y gallardo Capitán de las Milicias Reales, le iba la marcha montañera, trasegada con alambicadas etiquetas, pues en su abundante producción se repite insistentemente las referencias a la topografía y a los empadronamientos del Parnaso. Dos años antes había publicado sus Ocios de Castalia en diversos poemas (Málaga, Mateo López Hidalgo, 1663; 4º 16 hs.+231 hs.+1 h.+ 6 láms.) ${ }^{21}$ y años después saldrían su Justíssimo (aunque breve elogio) que las dos heroicas musas Clío y Caliope, cantan, celebrando el día de su alteza el sereníssimo Señor Don Juan de Austria (Málaga, Mateo López Hidalgo, 1677; 4 39 hs.); su Orfeo militar, cuya belicosa música celebra los felices triunfos, que en la Sagrada guerra de Viena y Buda an alcançado contra el Sultán de Assia las Imperiales Armas del César Leopoldo primero (Málaga, Mateo López Hidalgo, 1688; 4º 12 hs.+44 fols.+18 hs.+39 fols.) e incluso, el caso de su suplantación apolínea: Digníssimo panegírico que canta Apolo al muy excelente Señor Don Juan Francisco de la Cerda Enríquez (s. 1., s. i., s. a.; 4ํㅜ 33 hs.), amén de todo lo conservado autógrafo, donde sigue con los mismos presupuestos ${ }^{22}$.

Queda todavía entre las excepciones, la utilización nominativa para diferentes silvas teatrales, cuya mención del Parnaso no pasa de ser el gancho de un título editorial, con especial preferencia por las alegorías florales y la mención habitual de incluir siempre «los mejores ingenios»; casos, por orden cronológico, de los Verdores del Parnaso, en veinte y seis entremeses, bayles y sainetes, de diversos autores (Madrid, Domingo García Morrás, 1668; $8^{\mathrm{o}}, 4$ hs. +51 pp.+1 h.), con obras de Monteser, Diamante, Avellaneda, etc.; de la Primera parte del Parnaso nuevo y amenidades del gusto, en veinte y ocho entremeses, bailes y sainetes, de los mejores ingenios de España (Madrid, Andrés García de la Iglesia, 1670; 8o , 4 hs.+220 pp.), con textos anónimos y de Calderón, Moreto, Quirós, etc.; las Flores del Parnaso cogidas para recreo del entendimiento por los mejores ingenios de España, en Loas, Entremeses y Mojigangas (Zaragoza, Pascual Bueno, s. a., pero d. 1678; 8º 4 hs.+190 pp.), con piezas de Calderón, Bances Candamo, Olmedo, etc. y la recopilada por Gil de Armesto y Castro, Verdores del Parnaso, en diferentes Entremeses, Vayles y Mogigangas (Pamplona, Juan Micón, 1697; 8º 7 hs. +160 pp.), única de la que contamos con edición actual ${ }^{23}$. Excepción que se puede ampliar a dos recopilaciones musicales: el Libro de música en cifras para vihuela, intitulado el Parnasso, en el qual se hallará toda diversidad de Música, assí Motetes, Sonetos, Villanescas, en lengua 
Castellana, y otras cosas, como fantasías del autor de Esteban Daza (Valladolid, Diego Fernández de Córdoba, 1576; $4^{\circ}$ apaisado, 4 hs.+113 fols. de música anotada+1 h.) y el significativo conjunto coral del aragonés Pedro Ruimonte, El Parnaso español de madrigales $y$ villancicos a quatro, cinco y seis voces (Anvers, Pedro Phalesio, 1614; $4^{\circ}$ apaisado, 228 hs. de música anotada y gran grabado del Monte $)^{24}$.

21 Mencionadas las excepciones, quedan entonces aquellas obras en donde la voluntad recopilatoria -colectiva o individual- se presenta como una aspiración que equipara la constitución de su estructura como un modelo de Parnaso -laureado o sin laurear-, a la vez que refrenda la vinculación explícita del autor o de los autores con una transcendencia poética que les separa del resto de la plebe literaria. Son especialmente significativos, y por ello mejor y más detenidamente estudiados, los casos de la autoinmolación personal de nuestros mayores poetas áureos, en busca de una afirmación definitiva de la fama poética que sólo otorga la ascensión al pináculo del Parnaso, aunque eso sí, con arribo post mortem; lo que Ruiz Pérez ha dicho con otras palabras mucho más consecuentes: «Habría que considerar los procedimientos y elementos de canonización individual, incluida la autocanonización [...] la incorporación del poeta con protagonismo creciente a la tarea de consagración como tal» ${ }^{25}$.

Luis de Góngora no llegó a sugerir para su obra tan controvertido rótulo, aunque VélezSainz ha conceptuado el Manuscrito Chacón como unas «exequias textuales» del propio poeta $^{26}$, y fracasó la estrategia editorial del «Homero español» ideada por Juan López de Vicuña (Madrid, Alonso Pérez, 1627; 4ํㅜ 6 hs.+160 fols.) ${ }^{27}$; pero todo ello no fue óbice para que sí aparecieran -convenientemente descargadas de los textos más conflictivos- unas Delicias del Parnaso, en que se cifran todos los Romances Líricos, Amorosos, Burlescos, glosas, y décimas satíricas del regocijo de las musas el prodigioso don Luis de Góngora. Recogido todo de sus originales, y corregido de los errores con que estavan corruptos (Barcelona: Pedro Lacavallería, 1634; 12º 6 hs. +185 fols.) ${ }^{28}$; donde «El Impressor al Lector» (hs. 2v-3r) declara la busca de un Parnaso más popular, contando con la consideración sincrónica del Romancero como género menor: «De las obras del insigne Poeta don Luis de Góngora te ofrezco en este breve volumen lo más dulce, lo más donayroso, y lo más agradable [...] Agradece el reduzirte tantas delicias a brevedad tanta, para que puedas contigo llevar un jardín que te deleyte, y una diversión que te enseñe, construida de tan sazonadas agudezas, que igualmente te regozigen, te suspendan, y te admiren».

Lope de Vega, «Visorrey del Parnaso» como le llamaba Castillo Solórzano, sí que lo intentó en vida, y sin andarse por las ramas, cuando en la dedicatoria a la reina Ana de Austria de su Amarilis. Égloga a la reina christianísima de Francia (Madrid, Francisco Martínez, 1633; 8 32 fols.) indicaba que «Ya tengo el Parnaso [título del libro] en estado y presto bessará vuestra mano impreso». No sabemos qué contenía ni en qué orden, pero es muy probable que La vega del Parnaso por el Félix de España (Madrid, Imprenta del Reyno, 1637; 4 4 hs. +292 fols.) recoja buena parte de aquel proyecto, probablemente en un estado muy cercano al que pretendía el propio poeta; Pedraza Jiménez sugiere que El Parnaso se ajustaría «a la estructura de lo que hemos llamado "cancionero lopesco": una colección de sonetos, seguidos o precedidos de poemas variados y más extensos, unificado todo por el sentimiento dominante de cada etapa vital» ${ }^{29}$. En cualquier caso, el volumen parece que estaba ultimado en vida de Lope, pero con toda probabilidad lo que apareció en La vega del Parnaso sufrió alteraciones en su paso a la imprenta en lo relativo al orden y a su estructura y, claro está, en el título dado por los editores, su propio yerno y José Ortiz de Villena; así vuelve a sugerirlo Pedraza Jiménez, que estudia y analiza estos cambios y 
alteraciones, que se alejan ahora de nuestro interés inmediato ${ }^{30}$. Por no dejar de recordar, a otros efectos, pero siempre en su relación con el Parnaso, su Laurel de Apolo. Con otras Rimas (Madrid, Juan González, 1630; 80, 8 hs. +129 fols.+1 h.) ${ }^{31} \mathrm{y}$, en menor medida, su Isagoge a los Reales Estudios de la Compañía de Jesús (s. 1., s. i., s. a., pero ¿Madrid, 1629?; 8º 16 hs.) ${ }^{32}$. (No es de extrañar que Vicente Sánchez en su Lira poética [...] Obras pósthumas que saca a luz un aficionado al autor (Zaragoza, Manuel Román, 1688; 4, 18 hs. +312 pp. +2 hs.) rememore por boca de Montañés la contestación a un «poeta lego del Carmen que le ha bebido el aguachirle a Lope de Vega»: «Sepa que quien no ha leído a Góngora no se puede llamar poeta, pero usted me parece que no le ha visto. Ni a conocer quien es llega, / que en el Parnaso bifronte / Góngora va por el monte, / mas usted va por la vega.» ${ }^{33}$.)

Igual que Francisco de Quevedo, aunque de nuevo fuera un Parnaso de fama póstuma, cuyas titulaciones y estructura editorial lo denuncian a las claras, tanto en la edición de Joseph Antonio González de Salas, El Parnaso español, monte en dos cumbres dividido con las nueve Musas castellanas (Madrid. Diego Díaz de la Carrera, 1648; 4º, 8 hs.+666 pp., 7 láms.), como en la controvertida continuación de Pedro Aldrete Quevedo y Villegas, Las tres musas últimas castellanas. Segunda cumbre del Parnaso Español (Madrid, Imprenta Real, 1670; $4^{2}, 8$ hs. +358 fols.+4 hs., 4 láms.) $)^{34}$. En este nuevo Parnaso, y en competencia con la ceremonia de la profanación que promueve la necrofilia textual de Aldrete, el Virrey de Cerdeña, José Delitala y Castelví con su Cima del Monte Parnaso español con las tres musas castellanas Caliope, Urania y Euterpe, fecundas en sus assumptos por las varias poesías de Joseph Delitala y Castelví. Illustradas con unas diacrises, que preceden por Jayme Salicio (Caller, Onofrio Martín, 1672; 4 54 pp.+441 pp.+ 7 hs., 4 láms. ${ }^{35}$, se autoinmola poéticamente para completar esta «segunda cumbre» con sus propias poesías, pues como explica la «Diacrises» justificativa de Salicio, estando ya en las prensas la Cima se dan cuenta del robo denominativo que supone la edición de Aldrete y lo poco que aporta a la «remembranza» de la fama póstuma de la primera cumbre de Quevedo.

Para terminar esta larga escala parnasiana, y para ir terminando también mi propio descenso (que no aspira al «Premio de la Montaña» de ningún Tour), no hay más remedio que mencionar los intentos explícitos de consolidar un Parnaso modélico, con el requisito de la congregación de poetas en busca del lauro como representantes egregios de la fama poética. El primer caso es el del «Mercader de libros» aragonés José Alfay, Delicias de Apolo, recreaciones del Parnaso por las tres Musas Urania, Euterpe y Caliope. Hechas de varias poesías de los mejores ingenios de España (Zaragoza, Juan de Ybar, 1670; 4, 6 hs.+177 pp. [= 187]+1 h., 3 láms.), que se presenta (más o menos) como una «Segunda parte» de las divulgadas Poesías varias de grandes ingenios españoles, recogidas por Iosef Alfay y dedicadas a Don Francisco de la Torre, Cavallero del Ábito de Calatrava (Zaragoza Juan de Ybar, 1654, 4º 4 hs. +160 pp.+4 hs.) ${ }^{36}$, que ya había publicado en hacía casi 20 años, entonces como antología al modo de las Fiori transalpinas, pero con el añadido, ya barroco, del lexema «ingenio» (y recuérdese la sombra de la autoría recopilatoria de Gracián). Valga recordar, al paso, la importancia de las enunciaciones en los títulos, pues en la «Aprobación» de Juan Francisco Ginobés se lee, a cambio: «he visto este libro, intitulado Poesías varias de los mejores poetas de España»; Poesías donde se percibe un gusto por la "generación de 1650», Cáncer, Hurtado de Mendoza, con romances jocosos y burlescos de Góngora o Salas Barbadillo, mezcla de lo delicado con lo burlesco, lo introspectivo con lo satírico, etc. Sin embargo, en esta nueva salida editorial, donde se repiten algunos textos de 1654, aunque se inventan atribuciones a poetas famosos para eliminar nombres poco conocidos, se debe a que Alfay cargó con el gran resto de una edición madrileña titulada Delicias de Apolo, recreaciones del Parnaso por 
las tres Musas Urania, Euterpe y Caliope. Hechas de varias poesías de los mejores ingenios de España. Recogidas y dadas a la estampa por Don Francisco la Torre y Sevil, Cavallero del Ábito de Calatrava (Madrid, Melchor Alegre, 1670; 4ª 4 hs.+177 pp. $[=187])^{37}$ y la publicó en Zaragoza, sin nombre de recolector, cambiando cuatro hojas de preliminares, con la nueva dedicatoria, suprimiendo algunas composiciones y manteniendo el prólogo original, dedicadas ahora a Don Fernando Álvarez de Toledo. Curiosa mixtificación, cuanto menos, para uno de los primeros Parnasos colectivos y antológicos de nuestras letras áureas, cuyas primicias debemos retornar al benemérito Torre y Sevil, que ya veremos lo aficionado que se mostraba en trasuntos parnasianos.

Otra operación similar la perpetra el valenciano Juan Bautista Aguilar, autor (no queremos olvidarlo) de la Tercera parte (1688) de una de las obras claves de la mitografía barroca: el Teatro de los Dioses de la Gentilidad de Baltasar de Vitoria (Primera parte, 1620 y Segunda, 1623), su floresta se titula Varias hermosas flores del Parnaso, que en quatro floridos, vistosos quadros, plantaron junto a su cristalina fuente D. Antonio Hurtado de Mendoza, D. Antonio de Solís, D. Francisco de la Torre y Sevil, D. Rodrigo Artes y Muñoz, Martín Juan Barceló, Juan Bautista Aguilar y otros ilustres poetas de España. Cogiólas la curiosidad y recogidas las presenta el que las juntó curioso (Valencia, Francisco Mestre, 1680; 4ํㅜ, 8 hs. +216 pp.), con un relevante y significativo prólogo, y que tan sólo menciono ahora, pues nuestro hoy ausente amigo Juan Montero se ocupará de la que ha titulado como «última antología impresa de la lírica áurea». No obstante, le pido permiso para retrasar unos años esta fecha, si tiene a bien considerar otro florilegio, en esta ocasión hacia la vertiente religiosa y trasladándonos a las geografías orientales de San Francisco Javier, me refiero al Sacro Monte Parnaso de las Musas católicas de los Reynos de España, que unidas pretenden coronar su frente, y guarnecer sus faldas con elegantes poemas en varias lenguas. En elogio del prodigio de dos mundos, y Sol del Oriente San Francisco Xavier de la Compañía de Jesús, que recogidos y dispuestos con veinte y una láminas del Santo da a la estampa (Valencia, Francisco Mestre, 1687; 4, 12 hs.+ 1 h. plegada +267 pp.+ 2 hs., 21 emblemas), debido a la controvertida autoría del teólogo Francisco Ramón González, aunque una razonable atribución, corroborada en la «Aprobación» del libro y en la opinión de Martí Grajales, p. 274), la restituya al jesuita Vicente Claudio ${ }^{38}$. En el «Prólogo» de esta antología sacra (hs. 6r-8v), con algunos poemas en catalán, se desarrolla un programa de la constitución del Parnaso presentado como un contrafactum alegórico, asimilándolo al Santo, a su biografía, a sus virtudes, etc.; así Apolo es San Francisco Javier, Helicona las aguas del bautismo, el Sol (con toda evidencia) el Oriente y Vulcano, Neptuno, Atlante, etc. aparecen convenientemente caracterizados sobre la prosografía del Santo ${ }^{39}$.

Menos importante resulta, en la medida que se trata de poetas en algunos casos ya canonizados y ajenos a nuestras fronteras literarias áureas, la que propone el Académico de los Anfistilos de Roma, Gregorio de Tapia y Salcedo en su Monte Parnaso en seis cumbres (Madrid, s. i., 1658; 4ํ, 8 hs. + 54 pp., 1 lám.) que incluye poesías de Marcial, Ausonio, Tasso, etc., tanto en latín como en italiano, con sus traducciones respectivas en verso, sin que nos pase desapercibida -rememorando lo sucedido hacia dos escasos años con la primera cumbre de Quevedo- la titulación utilizada en forma de cordillera.

28 A estas vocaciones de formación de un Parnaso explícito -y llevamos ya unas cuantashabría que añadir un caso de aclimatación del Parnaso genérico -y en lógica geográfica: único- hacia otros territorios peninsulares bien lejos de las tierras helénicas. Así sucede con la narración en prosa y verso con dos comedias de Ambrosio Bondía, Cítara de Apolo y Parnaso en Aragón. A quien forman las doze sybilas, y las nueve Musas Apolíneas. Concurren las 
ciudades, $y$ las villas principales del Reino (Zaragoza, Diego Dormer, 1650; $4^{\circ}, 4$ hs.+676 pp.) ${ }^{40}$. Bondía traslada la residencia del Dios y sus acompañantes a las riberas del Ebro, de ahí el título y la frase final que cierra la obra: «y quedó célebre el Parnaso en Aragón por la Cítara de Apolo» (II, p. 579), con una topografía -«topotesia» en palabras de su editormuy precisa del entorno: Zaragoza, como ciudad solar, las riberas del Gállego, jardines, fuentes y la residencia teocéntrica de Apolo, su coro de Musas y el Monte como referente metapoético. (Un hipotético parnaso valenciano quedó en puertas sin cerrar después de un primer intento por parte de Jacinto Alonso Maluenda y su tribunal del Bureo de las Musas del Turia, en prosa y verso (Valencia, Miguel Sorolla, 1631; $4^{\circ}, 4$ hs. +144 pp. ${ }^{41}$, sin que Juan Bautista Aguilar, cincuenta años después, quisiera concretar esta ubicación.)

En los ribetes de la formación y desarrollo de este mito alpino no hay más remedio que mencionar otras obras que se instalan en las estribaciones del Parnaso y que ayudan a formarnos una impresión ciclorámica de la significación y la importancia de estos ascensos poéticos. Irremediable citar las influencias del Il viaggio di Parnaso de Cesare Caporali, incluido en sus Rimas piacevoli (Ferrara, Benedetto Mammarello, 1592) ${ }^{42} \mathrm{y}$, sobre todo, de los De' Ragguagli di Parnaso de Traiano Boccalini (la «Centuria prima» en Venecia, Pietro Farri, 1612 y la «Centuria seconda» en Venecia, Giovanni Guerigli, 1613), que aparte de las versiones originales se empiezan a difundir en las traducción de Fernando Pérez de Souza en sus Discursos políticos y Avisos del Parnaso (Madrid, María de Quiñones, 1634; 4, 17 hs. +220 fols,), sólo de la primera «Centuria», y ya completa en Madrid, Diego Díaz de la Carrera, 1653, 2 vols., 4², 14 hs.+177 fols.+1 h. y 6 hs.+144 fols.). Estas influencias llegan hasta el Viaje del Parnaso de Miguel de Cervantes (Madrid, Viuda de Alonso Martín, 1614; $8^{\circ}, 8$ hs. +80 fols. $)^{43}$, del que por motivos bibliográficos y de razonable cordura dejamos en la simple mención, y que a partir de él se desbordan por las letras barrocas.

Este empachamiento parnasiano que gravita sobre las letras españolas desde la segunda mitad del siglo XVI se amplía en textos como la poética del Cisne de Apolo, de las excellencias, $y$ dignidad $y$ todo lo que al Arte Poética y versificatoria pertenece. Los métodos $y$ estilos que en sus obras deve seguir el Poeta. El decoro y adorno de figuras que deven tener, y todo lo más a la Poesía tocante, significado por el Cisne, insignia preclara de los Poetas (Medina del Campo, Juan Godínez de Millis, 1602; 8º 16 hs.+214 fols.) de Luis Alfonso de Carvallo ${ }^{44}$; en los Christales de Helicona. Segunda parte de las rimas (Madrid, Díaz de la Carrera, 1649; $4^{\circ}, 24$ hs. +158 fols. $+2 / 3$ hs.) del comentarista gongorino García de Salcedo Coronel o en la Flor de Apolo (Bruselas, Baltazar Vivien, 1665; $4^{\circ}, 12$ hs.+ 256 pp.) y el Coro de las Musas (Bruselas, Baltazar Vivien, 1672; 12, 21 hs.+648 pp. [728]) de Miguel de Barrios; sólo por citar algunos ejemplos del inagotable manantial que proporcionan a la inspiración las castálidas aguas del Parnaso.

31 Se ha mencionado, y con razón ${ }^{45}$, la espectacular arquitectura efímera en la entrada en Madrid de la segunda esposa de Felipe IV, donde figuraba una representación del Monte, con las nueve Musas y un estatuario poemático donde se veían a los nueve autores canonizados: Séneca, Lucano, Marcial, Juan de Mena, Garcilaso de la Vega, Luis de Camões, Lope de Vega, Luis de Góngora y Francisco de Quevedo; todos ya muertos, es decir un Parnaso de la Fama eterna. Tenemos noticia directa, independiente de las menciones que afecta a Francisco de Quevedo a través de la biografía de Pablo Antonio de Tarsia, Vida de Don Francisco de Quevedo y Villegas (Madrid, Pablo del Val, 1663; 8º 8 hs.+181 pp.+14 hs. $)^{46}$, por la Noticia del recibimiento y entrada de la Reyna nuestra Señora Doña María Ana de Austria en la muy noble y muy leal coronada villa de Madrid (s. l., s. i., s. a., pero Madrid, ¿1650?; fol., 3 hs.+118 pp.), debida a Lorenzo Ramírez de Prado, aunque atribuida a Pedro 
Calderón de la Barca, que parece ser sólo colaboró, al igual que Juan Alonso Calderón, y que generó una amplia literatura festiva ${ }^{47}$. En ella, y a través de un pliego suelto, citamos una detenida descripción del Monte de nuestros desvelos, el titulado, Aquí se contienen unos esdrújulos por lo que se canta al Prado de San Gerónimo, de la partida del Rey nuestro Señor Felipe IV y la Reyna nuestra Señora Doña Mariana de Austria, del Escorial, entrada en el Prado y Real Retiro desta Corte, y fiestas que en él se les han hecho, y parabienes que se les da en las dichosas Bodas (Madrid: Diego Díaz, 1649; 4ํㅡ 2 hs., a 2 cols.), que mencionamos, a pesar de su pesada coba y su monotonía poética, porque uno de los ejemplares conocidos, se encuentra en el Ms/3.912 de la Biblioteca Nacional de España (hs. 190r-191r), que será nuestra llegada postrera en esta vuelta de la cumbre a la plácida llanura del silencio.

Quizá, de aquella deslumbrante escenografía de cartón piedra, le quedaron a Calderón de la Barca algunos recuerdos parnasianos que trasladó algunos años después a su Auto sacramental del Sacro Parnaso, incluido en la Descripción panegírica de las insignes fiestas que la Santa Iglesia Catedral de Jaén celebró en la translación del SS. Sacramento a su nuevo y sumptuoso Templo, por el mes de octubre del año de 1660 de Juan Núñez de Sotomayor (Málaga, Mateo López Hidalgo, 1661, pp.151-217, aunque hay también autógrafo y más de siete testimonios manuscritos), representado en 1659 con las piezas cortas del entremés de La rabia y su mojiganga, titulada precisamente, El Parnaso (manuscritos en la Biblioteca Nacional de España, Ms/15.596 y Ms/15.612, de mano del «pseudo Matos Fragoso» y en la Biblioteca del Instituto del Teatro de Barcelona, Ms $/ 46.820)^{48}$ por las compañías de Juan de la Calle y Sebastián de Prado ${ }^{49}$. En la «Memoria de las apariencias que se han de hacer en los carros para la representación de los autos, este año de 1659» se nos presenta la descripción escenográfica de lo que tuvo que ser para los espectadores de aquel momento la visualización del Monte Parnaso fuera del alcance de las alegorías textuales ${ }^{50}$ :

El primer carro [...] ha de ser una montaña hermosa, pintada de árboles, fuentes y flores. Desta, a su tiempo, ha de subir en elevación otra montaña, que en forma piramidal remate en disminución, y en lo eminente de la cumbre un sol entre nubarrones y rayos, y dentro dél un cáliz grande y una hostia. Lo demás deste segundo cuerpo ha de tener, a manera de nichos o quiebras de la misma montaña, lugares compartidos para diez ninfas, de las cuales, las cinco han de ser vivas, y las otras cinco pinturas cortadas de tabla, del tamaño natural de una mujer, de suerte que, incorporadas unas con otras, cubran toda la fachada, sin embarazarse las unas a las otras. Los dibujos de las pintadas han de ser vestidas como sibilas, que todas han de tener en sus lugares unas tarjetas, cuyos motes se darán a tiempo. Todo esto, como se ha dicho, ha de subir en elevación lo más que pueda y dar una y más vueltas al tablado.

No todo va a ser parabienes de la fecunda gloria poética en este pico tan literario, también -siempre también- en nuestra literatura gravitan la sátira, la ironía y la crítica jocosa hacia tanta pompa, tanta deidad y tanta empalagosa exaltación. Pespuntearé, antes de terminar, algunas calas. La fastuosa entrada regia de 1649 también dejó una «Descripción burlesca del Monte Parnaso que se levantó en el Prado de Madrid, quando entró en él la Reyna nuestra Señora. Pidió esta relación una Señora que no la pudo ver», trovada en 22 quintillas de tono satírico sobre la tramoya parnasiana

Aunque mi talento escaso

por ti la obra más estraña,

le es fácil, en este caso,

hermosa Laura, el Parnaso

se me haze una montaña

incluida, -y me atrevo a la atribución con mi llorado amigo Pepe Oltra $^{51}$ - en el Entretenimiento de las Musas en esta baraja nueva de versos, dividida en quatro manjares 
de asuntos sacros, heroicos, líricos y burlescos (Zaragoza, Juan de Ybar, 1654; 4, pp. 150-154) de Feniso de la Torre, que no es otro que el disfraz literario de nuestro viejo conocido parnasiano Francisco de la Torre y Sevil ${ }^{52}$.

Años antes Juan de la Cueva nos dejó otro testimonio bien significativo, el romance "Cómo los Poetas conquistaron el Parnasso, y Apolo y las Musas huyeron dél», incluido en su Coro Febeo de romances historiales (Sevilla, Juan de León, 1588; 8으, fols. 316v-324r); donde relata (con harta brevedad por mi parte), que aburrido Apolo porque muchos poetas no se ajustaban a las normas y despreciaban la antigüedad

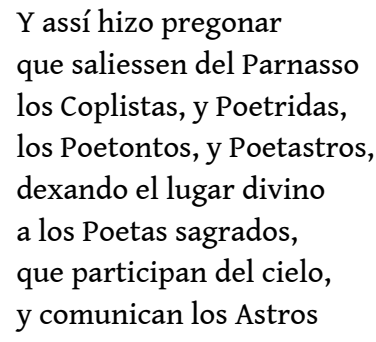

ante el pregón divino, una multitud de afectados se juntan en la Arcadia y se dirigen al Monte, y a pesar de que Apolo les hace frente con la ayuda de las Musas, éstos con sus armas "cual le tira un cancionero / cual le tira el novelario», no puede impedir la invasión que aunque derrivavan muchos,

ivan sucediendo tantos

que parecía que el Monte

poetas iva brotando.

En 1624 es Feliciana Enríquez de Guzmán quien incluye en los paratextos de la Tragicomedia de los jardines y campos Sabeos (Coimbra, Iacome Carvallo, 1624; 4, 12 hs. +36 hs.) una Carta executoria enviada por Apolo desde el Parnaso donde se ridiculiza el Parnaso madrileño y se defiende de las normas de la composición teatral. Va dirigida: «A la serenísima princesa de las ciencias, Pallas Minerva y a las nueve infantas de nuestro Parnaso y Consejo Real de Poesía, nuestras muy caras y muy amadas hermanas, duques, condes, marqueses, ricos hombres, presidentes y oidores de nuestras audiencias y cancillerías, etc. Y a todos los poetas españoles, que andáis vagando por las faldas y cumbres de nuestro sacro Monte, salud y gracia» y se desarrolla a modo de querella que reclama una sentencia, sentencia que al final se otorga: «Dada en los jardines de nuestro Monte Parnaso, en primero de marzo de mil y seiscientos y veinte y cuatro», rubricada por «Apolo Febo, Calíope, Euterpe [y] Talía» y «por su mandado Orfeo de Tracia, Secretario. Registrada $»^{53}$.

De estas fechas son los Donayres del Parnaso, «Primera y Segunda parte» de Alonso de Castillo Solórzano (Madrid, Diego Flamenco, 1624; 8, 8 hs.+132 fols. y Madrid, Diego Flamenco, 1625; $8^{\mathrm{o}}, 6$ hs.+126 fols. ${ }^{54}$, jocosa peregrinación donde el poeta, jugando con su condición de hombre cortesano, satiriza algunos de los aspectos más relevantes de las academias parnasianas: el rapto de las Musas, la bebida en la fuente Aganipe, etc.; en el fondo no pretende otra cosa que la entronización personal, tras un repaso irónico de los pretendientes menos favorecidos. Muy distintas, y desde luego en un tono de burla mucho más comedido, son las Coronas del Parnaso y Platos de las Musas (Madrid, Imprenta del Reino, 1635; $8^{\circ}$, 8 hs.+310 fols.) del novelista Alonso Jerónimo de Salas Barbadillo, las primeras dedicadas al Conde Duque y los segundos a «los venerables ingenios, ornamento y felicidad de la Patria». Esta abigarrada miscelánea literaria, compuesta de un buen número de poesías, 4 entremeses, 2 comedias, 1 fábula en verso y otra en prosa, más una novela representa una contienda enmascarada de guerra y de banquete literario, que se 
inicia cuando Apolo funda unas Escuelas para premiar a los mejores poetas y, mientras Italia envía a numerosos aspirantes, España ninguno; pero ello se repara más tarde al llegar a la corte del Parnaso tres poetastros, que Apolo, aleccionado por sus consejeros Garcilaso, Figueroa y Cervantes como poetas ya canonizados, someterá a una batalla entre los malos y los buenos poetas en la «Festividad del español mecenas», que no es otro que el Conde Duque. La obra es una apología del mecenazgo, pero refleja una visión muy completa de la mentalidad parnasiana de un estado de la poesía, las cortes literarias y el estado nominal de los poetas laureados ${ }^{55}$.

Hay más textos, como el furibundo ataque al Duque de Osuna de Valerio Fulvio, enmascarado con el título de Avviso di Parnaso. Nel quale si racconta la povertá, e miseria, dove e giunta la Republica di Venetia, et il Duca di Savoia. Scritto da un curioso Novellista Spagnolo. Con alcune annotationi (Antolopi, s. i., 1618; 4², 60 pp.), con continuaciones y añadidos o en 1645 la «Opera burlesca di Carmenio da Metaponto fatta contra il Marino, divisa en due libri, uno in versi e l'altro in prosa» (manuscrito de la Biblioteca Nacional de España, Ms/1.468; $4^{\circ}$, 366 fols.) de Tommaso Stigliani ${ }^{56}$, dirigida contra uno de los más acervos defensores de las laderas parnasianas.

Toca el fin este viaje de ida, pero ya de vuelta del Parnaso, con un pequeño enigma. Antes he mencionado el manuscrito Ms/3.912 de nuestra Biblioteca Nacional de España, que encabeza un conjunto de 14 volúmenes de códices misceláneos y facticios (y/o facticios/ misceláneos) -aunque faltan de antiguo los números IX, XI, XII- que representan un acrisolado mausoleo de la poesía española del siglo XVII hasta comienzos del siglo XVIII (Biblioteca Nacional de España, Ms/3.912-3.922 [olim: M/1-13]) ${ }^{57}$. Volúmenes manuscritos, con esporádicos impresos menores, autónomos e independientes, de distintas procedencias, organizaciones y extensión, de diferentes temas y motivos, algunos con obras teatrales, otros casi cancioneros particulares de algún autor, de prácticamente todos los poetas que escribieron en el siglo XVII y comienzos del siglo XVIII. Sólo les hermana una encuadernación unitaria en pergamino a la romana que ha dejado rotulado en los lomos, escuetamente: «Parnaso Español»; no sé (con seguridad ni todavía) quién reunió este catastro literario ni quien encargó esta vestidura ni las razones de la voluntaria denominación de este panteón poético, pero parece evidente que quien se molestó en congregar este parnaso no dudó en recordárnoslo como tal, ajeno a discutir ninguna contienda crítica ni literaria, pues, al fin y al postre, la poesía es lo que queda después de quitar (toda) la retórica poética.

Estos paseos por la memoria suelen servir para recordar lo que ya se sabía y tal vez se olvidó, por ello y después de haber escuchado tantos afanes literarios de aquellos momentos áureos (y de estos días presentes), ya sabemos que no hay canon, sino cánones, y que también hay otros Parnasos pero están en éste; en cualquier caso, su mención evoca la patria simbólica del autor literario, reflejada en una historia editorial que dibujó para siempre en letras de molde las sombras impresas de una ilusión poética con nombre de montaña. 


\section{NOTAS}

1. Vid. General Estoria. Quinta parte, fol. 55v, edición de Pedro Sánchez Prieto, Alcalá de Henares, 2002, que por utilidad citamos en Real Academia Española, 2007. Banco de Datos (CORDE). Corpus diacrónico del español. <http://corpus.rae.es/cordenet.html> (Junio, 2007).

2. Julio Vélez-Sainz, El Parnaso español: canon, mecenazgo y propaganda en la poesía del Siglo de Oro, Madrid: Visor Libros, 2006; más tarde citaremos, a otros propósitos, la Tesis Doctoral que dio origen a esta publicación.

3. Inútil reseñar una mínima cobertura bibliográfica, pero, por época y cercanía teórica debe señalarse el colectivo de Grupo PASO, VII Encuentro Internacional sobre Poesía del Siglo de Oro (Universidad de Sevilla, 20-22 de noviembre de 2003). En torno al canon: aproximaciones y estrategias, Begoña López Bueno, ed., Sevilla: Universidad de Sevilla, 2005.

4. Pedro Ruiz Pérez, «En los inicios del canon lírico áureo», Voz y Letra. Revista de Literatura, XV/1 (2004), pp. 25-52, en particular p. 28; además, «El Parnaso se desplaza: entre el autor y el canon», en Grupo PASO, cit., pp. 197-232.

5. J. Vélez-Sáinz, El Parnaso, cit., p. 195.

6. Las obras, que son algunas, se citan de la forma más abreviada posible, sin necesidad de un arrope bibliográfico de descripción, localizaciones, citas, referencias, etc.; se manejará, siempre que sea posible, la edición original y se citará, según los casos, una edición más o menos moderna de consulta.

7. P. Ruiz Pérez, «En los inicios», cit., p. 48.

8. Edición facsímile de Antonio Rodríguez-Moñino, Madrid: RAE, 1958, el «Prólogo» en hs. 1r-2v.

9. Edición de Carlos Clavería, Barcelona: Delstre's, 1993; se debe añadir, específicamente, Juan Montero, «La poesía del Siglo de Oro en sus antologías impresas: el Cancionero General de Obras Nuevas (Zaragoza, Esteban de Nájera, 1554)», en Grupo PASO, cit., pp. 413-438.

10. Edición de Antonio Pérez Gómez, Barcelona: Selecciones Bibliófilas, 1950, 2 ts., citamos por esta edición, ante la complejidad estructural de las partes del impreso original.

11. Vid. Pedro Ruiz Pérez, «Espejos poéticos y fama literaria: las epístolas en verso del siglo XVI», Bulletin Hispanique [Penser la littérature espagnole], 1 (juin 2004), pp.45-81 y, páginas y épocas anteriores, Víctor Infantes, «Espejos poéticos y fama literaria. Las nóminas de autoridades líricas (siglos XV-XVII)», idem, pp. 23-44.

12. Edición facsímile de Alonso Zamora Vicente, Madrid: RAE/Unicaja, 1991 y ediciones de Belén Molina Huete, Sevilla: Fundación Lara, 2005, con estudio de la misma autora La trama del ramillete: construcción y sentido de las «Flores de poetas ilustre» de Pedro de Espinosa, idem, 2003, e Inoria Pepe Sarno y José María Reyes Cano, Madrid: Cátedra, 2006.

13. Edición de Juan Quirós de los Ríos y Francisco Rodríguez Marín, Sevilla: Imprenta de E. Rasco, 1896.

14. Edición facsimile de Antonio Rodríguez-Moñino, Las fuentes del Romancero General (Madrid, 1600), Madrid: RAE, 1957, t. X.

15. Edición facsímile, New York: The Hispanic Society of America, 1902 y edición moderna de José del Río, Madrid: Cisneros, 1943; vid., específicamente, Antonio Rodríguez-Moñino, «Las Maravillas del Parnaso. Romancerillo del Siglo de Oro (1637-1640). Noticias bibliográficas», Anuario de Letras, I (1961), pp. 75-98.

16. Edición facsímile de Trinidad Barrera López, Roma: Bulzoni, 1990 y de la misma autora, «La Primera parte del parnaso antártico de Diego Mexía de Fernangil, Sevilla, 1608», en Bibiano Torres Ramírez y José Hernández Palomo, eds., Actas de las III Jornadas de Andalucía y América. Universidad 
de Santa María de la Rábida, marzo-1983, Sevilla: CSIC, III, 1985, pp. 213-229. La famosa diatriba de Ovidio contra el enemigo que se oculta bajo el nombre de Ibis, titulada «La invectiva contra Ibis de Ovidio Nasón», fols. 241r-265r, se reimprime en facsímile tras la obra de Fray Cristóbal Mansilla, Invectiva contra el heresiarcha Luthero (Burgos, 1552). Con el In Ibin de Ovidio en la versión castellana de Diego Mexía (Sevilla, 1608), Cieza: El ayre de la almena (IV), 1961, con «Noticia bibliográfica» de Antonio Pérez Gómez, s/p.

17. Citamos ahora la Tesis Doctoral de Julio Vélez-Sainz, The Spanish Parnaso: canon, patronage and propaganda in the Golden Age, University of Chicago, 2002, 2 ts, porque aquí sí se ocupa de este autor (y de otros), II, pp. 377-388, y es parte suprimida, como «Apéndice I»: «Parnasos antárticos. El nacimiento de la literatura peruana (Diego Mexía, «Clarinda»)», en la publicación de 2006, $c f$., infra, nota 2.

18. Edición de Giuseppe Bellini, Roma: Bulzoni, 1997 y más reciente de Luis García-Abrines Calvo, Juan del Valle y Caviedes, Obra poética 1. Diente del Parnaso (Manuscrito de la Universidad de Yale), Jaén: Diputación Provincial de Jaén, 1993, texto en pp. 125-411 y nuestras citas en pp. 130-131, en las que mantenemos las características del original.

19. Edición de Emilio Cotarelo y Mori, Madrid: Colección selecta de antiguas novelas españolas (XII), 1909, aunque el estudio está en el vol. X, que tienen El Menandro, idem (X), 1909, pp. VIIXXXI; la cita en p.11; vid., además, Begoña Ripoll, La novela barroca. Catálogo bio-bibliográfico (1620-1700), Salamanca: Universidad de Salamanca, 1991, pp. 136-137.

20. Poemas lúgubres. "Corpus elegiarum» en memoria de la muerte de su esposa, edición de Cristóbal Cuevas, textos latinos de Francisco Talavera, Málaga: Diputación de Málaga, 1989.

21. Hay edición de Cristóbal Cuevas, con textos latinos de Francisco Talavera, Málaga: Diputación de Málaga, 1987, pp. 15-42, con reproducción facsímile de la descripción de Málaga, edición de Ángel Caffarena, Málaga: Librería Anticuaria el Guadalhorce, 1965.

22. Vid. Autógrafos (Manuscrito Muñoz Rojas), edición de Cristóbal Cuevas y Salvador Montesa Peydro, Málaga: Diputación de Málaga, 1997.

23. Edición de Rafael Benítez Claros, Madrid: CSIC, 1969.

24. Edición de Pedro Calahorra, Zaragoza: Institución «Fernando el Católico», 1980.

25. P. Ruiz Pérez, «En los inicios», cit., p. 48.

26. J. Vélez-Sainz, El Parnaso, cit., pp. 85-93; hay edición facsímile moderna de Madrid: RAE, 1991, 3 vols.

27. Hay edición facsímile de Dámaso Alonso, Madrid: CSIC, 1963.

28. Edición, con algunas reproducciones, New York: The Hispanic Society of America, 1927 y edición facsimile Madrid: Espasa-Calpe, 1977; se supone una edición del mismo impresor de 1630, sin confirmar.

29. Edición facsímile de Felipe B. Pedraza Jiménez, Madrid: Ara Iovis, 1993, la cita en p. IX.

30. Edición de F. Pedraza Jiménez, cit., supra, pp. IX-XII.

31. Edición de Christian Giaffreda, Florencia: Alinea, 2002, con «Introduzione» de Maria Grazia Profeti y (bien) reciente de Antonio Carreño, Madrid: Cátedra, 2007.

32. Vid. edición de Antonio Carreño, Lope de Vega, Obras completas. Poesía V, Madrid: Fundación José Antonio de Castro, 2004, pp. 415-437; no escapó su relación con nuestro tema a José Simón Díaz, «El Monte Parnaso en cinco obras del Siglo de Oro», Anales de Literatura Hispanoamericana [ Homenaje a Francisco Sánchez Castañer], VIII (1979), pp. 273-288., en particular, p. 284.

33. Edición de Jesús Duce García, Zaragoza: Prensas Universitarias de Zaragoza, 2003, la cita en p. 94.

34. De la primera hay edición facsímile de Felipe B. Pedraza Jiménez y Melquiades Prieto Santiago, Madrid: EDAF, 1999 y a su presentación remitimos.

35. Edición de Louis Saraceno, New York: Peter Lang, 1997.

36. Edición de José Manuel Blecua, Zaragoza: Institución Fernando el Católico, 1946. 
37. Vid. buena parte de esta compleja trama bibliográfica en Antonio Rodríguez-Moñino, Manual bibliográfico de cancioneros y romanceros I. Impresos durante el siglo XVII, Arthur L-F. Askins, coord., Madrid: Castalia, 1977, I, no 245, donde se reproduce el artículo de John M. Hill, «Notes on Alfay’s Poesías varias de grandes ingenios», Revue Hispanique, LVI (1922), pp. 423-433, pp. 638-646; no 251 у nº 252.

38. Francisco Martí Grajales, Ensayo de un diccionario biográfico y bibliográfico de los poetas que florecieron en el Reino de Valencia hasta el año 1700, Madrid: Tip. de la «Revista de Archivos, Bibliotecas y Museos», 1927, pp. 274-275.

39. Una breve edición antológica presentan Gabriela Torres e Ignacio Arellano, El prodigio de dos mundos, San Francisco Javier, y el Sacro Parnaso de las musas católicas, Pamplona: Pliegos volanderos del GRISO, 2002.

40. Edición de José Enrique Laplana Gil, Huesca/Zaragoza: Instituto de Estudios Altoaragoneses/ Institución Fernando el Católico, 2000.

41. Edición de Eduardo Juliá Martínez, Madrid: CSIC, 1951.

42. Edición de Norberto Cacciaglia y Claudio Contulo, Perugia: Guerra, 1993.

43. Edición facsímile en Madrid: RAE, 1917 (con los Trabajos de Persiles y Segimunda) y edición de Miguel Herrero García, Madrid: CSIC, 1983.

44. Edición de Alberto Porqueras Mayo, Madrid: CSIC, 1958, 2 vols.

45. Vid. J. Vélez Sáinz, El Parnaso, cit., especialmente, p. 17.

46. Edicion facsímile en Cuenca: Universidad de Castilla-La Mancha, 1997, la cita que interesa en fol. $27 \mathrm{v}$.

47. Vid. la extensa recopilación de Jenaro Alenda y Mira, Relaciones de solemnidades y fiestas públicas de España, Madrid: Establecimiento Tipográfico «Sucesores de Rivadeneyra», 1903, pp. 304-321 y análisis importante, con la presencia calderoniana, de John E. Varey y Abdón M. Salazar, «Calderón and the Royal Entry of 1649», Hispanic Review, XXXIV (1966), pp. 1-26.

48. Vid. Agustín de la Granja, "Cinco obrillas cortas atribuibles a Calderón», Bulletin Hispanique, LXXXV (1984), pp. 355-378 y Mª Luisa Lobato, «Una mojiganga inédita de Calderón: El Parnaso. Segunda parte de La rabia», en Estudios sobre Calderón (Actas del Coloquio Calderoniano de Salamanca, 1985), Salamanca: Universidad de Salamanca, 1988, pp.71-90. Hay edición reciente de Alberto Rodríguez Rípodas, El sacro Pernaso, con estudio introductorio de Antonio Cortijo y facsímile del manuscrito de la Biblioteca Municipal de Madrid, Pamplona/Kassel: Universidad de Navarra/ Reicheberger, 2006.

49. Vid. Héctor Urzáiz Tortajada, Catálogo de autores teatrales del siglo XVII, Madrid: FUE, 2002, I, p. 202 y p. 206; J. Simón, «El Monte Parnaso», cit., pp. 286-288 y edición de Eduardo González Pedroso, Autos sacramentales desde sus orígenes hasta fines del siglo XVII, Madrid: BAE (58), pp. 364-383, reproduciendo la «Memoria».

50. Seguimos la descripción que ofrece (y transcribe) J. Simón Díaz, «El Monte Parnaso», cit., p. 286.

51. Vid. José Miguel Oltra Tomás, «Un mundo para un certamen: aproximación a la Palestra Numerosa Austriaca de Huesca (1650)», en José Enrique Laplana Gil, ed., Actas del I y II curso en torno a Lastanosa. La cultura del Barroco. Los jardines: arquitectura, simbolismo y literatura, Huesca: Instituto de Estudios Altoaragoneses, 2000, pp. 93-110, en particular, p. 99.

52. Edición de Manuel Alvar, Valencia: Universidad de Valencia, 1987, pp. 232-235.

53. Edición de Teresa Scott Soufas, Women's Acts. Plays by Women Dramatists of Spain's Golden Age, Lexington: Kentucky University Press, 1997, pp. 268-270.

54. Edición de Luciano López Gutiérrez, Madrid: Tesis Doctoral de la Universidad Complutense, 2003; pueden sumarse las palabras de J. Vélez-Sainz, El Parnaso, cit., pp. 116-122.

55. Vid. J. Vélez-Sáinz, El Parnaso, cit., pp. 116-125 y J. Simón Díaz, «El Monte Parnaso», cit., p. 285.

56. Edición de $\mathrm{M}^{\mathrm{a}}$ Dolores Valencia Mirón, Lo Scherzo di Parnaso de Tommaso Stigliani (Ms. 1468 B. N. De Madrid), contribución al estudio del antimarinismo, Granada: Universidad de Granada, 1987. 
57. Vid. descripciones en José Simón Díaz, Bibliografía de la literatura hispánica, Madrid: CSIC, $1972^{2}$, IV, $\mathrm{n}^{\circ}$ 3.191; Inventario general de manuscritos de la Biblioteca Nacional, Madrid: Ministerio de Cultura, 1984, pp. 212-214 y, sobre todo, Catálogo de manuscritos de la Biblioteca Nacional con poesía en castellano de los siglos XVI y XVIII, Madrid: Arco/Libros, 1998, II, pp. 1.089-1.230.

\section{RESÚMENES}

Panorámica general de la presencia del concepto y del término de «Parnaso» a lo largo de diferentes testimonios de la literatura española de los siglos XVI y XVII, analizando su utilización y su sentido teórico y poético en obras de autores individuales y en antologías.

Vision panoramique concernant la présence de la notion et du terme de «Parnasse», à travers différents témoignages de la littérature espagnole des XVI ${ }^{\mathrm{e}}$ et XVII ${ }^{\mathrm{e}}$ siècles, avec une analyse de l'emploi et de la signification théorique et poétique du mot dans des œuvres individuelles et anthologiques.

A general survey of the occurrence of the concept and the word «Parnaso» in Spanish litterature during the 16th and 17th centuries. An analysis is made of the use and the theoretical and poetic meaning of this word in literary works of individual authors and anthologies.

\section{ÍNDICE}

Mots-clés: Parnasse, poésie du Siècle d'or

\section{AUTOR}

\section{VÍCTOR INFANTES}

Universidad Complutense de Madrid 